thesis, these in their turn would produce a secular magnetic change.

(y) Regarding Earth Currents and Auroras.-I have for some considerable time looked on the earth as a Ruhmkorff's coil with a magnetic nucleus. Above this nucleus we may suppose that we have the primary rocks, which are non-conductors, while above these we have the moist or comparatively moist surface of the earth, which is a conductor. Above this, again, we have the lower strata of the atmosphere, which are non-conductors, while above this we have the upper strata, which are conductors.

Now suppose that a small but abrupt change of the earth's magnetism takes place, no matter how. We need not enter into the causes of such.

We have thus two secondary coils, if I may use the expression: (I) the moist surface of the earth, (2) the upper regions of the atmosphere; and both of these will be animated with secondary currents, on account of the abrupt change of the earth's magnetism. These secondary currents will be in one direction for a magnetic change of one kind, and in the opposite direction for a magnetic change of the opposite kind.

Now whenever there are magnetic storms, that is to say, when there are small but abrupt changes of the earth's magnetism, it is well known from the Greenwich records that we have violent earth currents, which are alternately positive and negative, and that we have also auroral displays in the upper regions of the earth's atmosphere. We cannot examine the auroral displays as we can the earth currents. But with regard to earth currents I would remark that the form of the phenomena they display is entirely against the supposition that such currents are the main cause of the changes in terrestrial magnetism, and in favour of that which maintains that they are secondary currents induced by magnetic changes.

In conclusion I would guard against its being supposed that all luminous appearances in the atmosphere are due to the same cause. I only hold that certain appearances which occur at times of magnetic perturbation and simultaneously throughout a large portion of the earth have the origin now mentioned.

B. STEWART

\section{ON A NEW FELLY-FISH OF THE ORDER TRACHOMEDUSA, LIVING IN FRESH WATER}

$\mathrm{O}^{\mathrm{N}}$ Thursday last, June Io, Mr. Sowerby, the secretary of the Botanical Society of London, observed in the tank in the water-lily house in Regent's Park a peculiar organism, of which he was kind enough to place a large number at my disposal on the following Monday.

The organism proves to be an adult medusa belonging to the order Trachomedusæ and the family Petasidæ of Haeckel's system ("System der Medusen," erster Theil). It comes nearest among described genera to Fritz Müller's imperfectly known Aglauropsis from the coast of Brazil.

The most obviously interesting matter. about the form under notice is that it occurs in great abundance in perfectly fresh water at a temperature of $90^{\circ} \mathrm{Fahr}$.

Hitherto no medusa of any order has been detected in fresh water-except perhaps some stray estuarine forms (? Crambessa).

It is exceedingly difficult to trace the introduction of this animal into the tank in the Regent's Park, since no plants have been recently (within twelve months) added to the lily-house, and the water is run off every year. Probably a few specimens were last year or the year before present in the tank, and have only this year multiplied in sufficient abundance to attract attention. Clearly this medusa is a tropical species, since it flourishes in water of the high temperature of $90^{\circ} \mathrm{Fahr}$.

Mr. Sowerby has observed the medusa feeding on Daphnia, which abcunds in the water with it.
The present form will have to be placed in a new genus, for which I propose the name Craspedacusta, in allusion to the relation of its otocysts to its velum.

It is one of the sub-class Hydromedusæe or Medusa craspedotæ, and presents the common characters of the order Trachomedusæ (as distinguished from the Narcomedusæ) in having its genital sacs or gonads placed in the course of the radial canals. It agrees with all Tracholinæ (Trachomedusæ and Narcomedusæ) in having endodermal otocysts, and it further exhibits the solid tentacles with cartilaginoid axis, the centripetal travelling of the tentacles, the tentacle rivets (Mantelspangen), the thickened marginal ring to the disk (Nessel ring) observed in many Tracholinæ.

Amongst Trachomedusæ, Craspedacusta finds its place in the Petasidæ, which are characterised as "Trachomedusæ with four radial canals, in the course of which the four gonads lie, with a long tubular stomach and no stomach-stalk."

Amongst Petasidæ it is remarkable for the great number of its tentacles, which are all solid; and for its very numerous otocysts. Further, it is remarkable among all Hydromedusæ (velate medusæ, that is, exclusive of Charybdæa) for the fact that centrifugal radiating canals pass from the otocysts into the velum, where they end cacally.

The genus may be characterised as follows :-

MOUTH quadrifid, with four per-radial lobes.

STOMACH long, quadrangular, and tubular, projecting a good deal below the disk.

Disk, saucer-shaped, that is, flattened.

RADIATING CANALS 4, opening into the marginal canal.

GONADS 4 , in the form of 4 oval sacs, depending into the cavity of the subumbrella from the four radiating canals.

MARGINAL or RING CANAL voluminous.

Centripetal Canals (such as those of Olindias, Geryonia, \&c.) absent.

TENTACLES solid; in three sets, which are placed in three superimposed horizons :-

I. A set nearest the aboral pole, of 4 large per-radial tentacles. These are the primary tentacles.

2. A second tier of (in large specimens) 28 mediumsized tentacles placed between these in four groups of seven. These are the secondary tentacles.

3. A third tier of (in large specimens) 192 small tentacles placed in groups of six between adjacent secondary tentacles. These are the tertiary tentacles.

TENTACLE-RIVETS (Mantel-spangen) connecting the roots of the tentacles with the marginal ring (Nessel-ring) are connected with all the tentacles of each of the three horizons.

OTOLITHS placed along the line of insertion of the velum - about eighty in number (fewer in small specimens). From sixteen to twenty are placed between successive perradial tentacles arranged in groups of two or three between the successive secondary tentacles.

VELAR CENTRIfugal Canals (which are really the elongated otocysts) are peculiar to this genus, passing from the otoliths (one inclosing each otolith) into the velum, and there ending blindly. They appear to correspond in character to the centripetal canals found in other Trachomedusæ in the disk.

OCELLI are absent.

[The presence of velar otocystic canals constitute the chief peculiarity of the genus Craspedacusta, and may necessitate the formation of a distinct family or sub-order for its reception. The minute structure of the otoliths and canal-like otocysts I am now engaged in investigating.]

The above characters are derived from the examination of adult male specimens, which were freely discharging ripe, actively motile spermatozoa. 
The species may be known as CRAspedaCUsta SOWERBII, nov. gen. et sp.-I name the species in honour of $\mathrm{Mr}$. Sowerby, who discovered it, and to whose quick observation and courteous kindness zoologists are indebted for the knowledge of this interesting animal.

The sole character which I can give as specific over and above the generic characters summarised above is that of size. The diameter of the disk does not exceed one-third of an inch.

Locality.-The water-lily tank in the gardens of the Botanical Society, Regent's Park, London.

Very abundant during June, i880. Probably introduced from the West Indies.

E. RAY LANKESTER

\section{NOTES FROM FAVA}

$\mathrm{T}$

$\mathrm{HE}$ following extracts from a letter written from Java by Mr. Henry O. Forbes to Mr. H. N. Moseley, F.R.S., have been sent to us for publication as of consi-
derable interest. The letter is dated March I9. Mr. Forbes, who has been engaged in collecting in Java, expects shortly to leave for Celebes, Timor, Timor-laut, and other eastern islands. Timor-laut is the most important island of the Malay Archipelago yet remaining to be explored, and is likely to yield many natural history treasures. Mr. Forbes's letter refers to certain passages in Mr. Moseley's "Notes by a Naturalist on the Challenger." The question of the mode of growth of Myrmecodia and Hydrophytum has been lately before the Linnean Society.

"With regard to birds carrying seeds from one island to another, I have observed on the Cocos Keeling Islands (South Indian Ocean) a species of heron which nested in a high tree (species unknown) there, quite covered with its oblong hooked seeds. I was informed by the proprietor of the island that many of these birds, from their feathers getting so thickly covered with the seeds, actually die. I can therefore imagine that many of these seeds might adhere for even weeks and months, and so get transported to very distant regions.

"At p. 493 you note the habit of hot-water drinking. It is quite a custom among, at any rate, the Sudanese, among whom I have been living some time, who, in the afternoons, invite each other to come and have a cup of hot water. It is drunk either plain or with a little arenga sugar.

"I have found here a large quantity of algæ growing in the hot springs at a temperature of $132^{\circ} \mathrm{F}$. What the species are or is I have not yet ascertained.

"With reference to Myrmecodia and Hydnophytum, I find some difficulty in reconciling in all cases the statement (p. 389) that 'the ants gnaw at the base of the stem, and the irritation produced causes the stem to swell,' with what I have myself observed. I have grown many young seedlings, some of which were entirely unmolested by ants, and yet produced a bulbous swelling at the base; others were certainly scratched, but that was all, by the ants, the smallest scar being visible. On opening many of those which were unmolested I observed a degenerated, soft, spongy portion, not in connection with the exterior. May not this spot increase till an external opening is formed, and the ants have an entrance made for them to carry out, as I have seen them doing, the soft spongy substance inside? I have seen other secdlings that had a small orifice close to the rootlet, leading into an interior oval or round expansion in the bulb, and though I closely observed them I failed to detect ants touching them. All these seedlings I grew from the seed till they reached at most a couple or three inches or a little more, when they generally became the home of some ants. After they had become infeste 1 I did not pursue observations on them, as my time was much occupied, and because the object of my observation was to discover if they bulbed, \&c., without the aid of ants. I should much like to see these plants grow with all ant life removed from them entirely. If opportunity again offers I shall continue my experiments. I have repeatedly noticed on large Myrmecodia and Hydnophyta which were crowded with ants (on both genera I have found only one species of ant) that in many places irregularlyshaped areas of degeneration existed quite cut off from communication with the wonderful series of galleries and chambers which form this ant-hive. These were found oftenest near the upper portion of the bulb, and towards which excavations were being directed. I have not. observed that the surface of the rounded mass gives off any twigs bearing leaves or flowers. All my specimens have had the shape of a bulb more or less gobose, or elongate, prickly, tenanted by ants, giving origin to a much thinner stem, not, or rarely, chambered nor passaged, but also armed, and from which the leaves and sessile flowers proceeded, the latter from hollows in which numerous ants were constantly moving about. The Hydnophyta generally give off at once leaves at the summit of a more or less irregular bulb.

"I have seen the same species of ant inhabiting the swollen-up hollow leaves of a species of Hoya or Eschynanthus. The plant I saw had many of its leaves in this condition. I gathered it one day while on the march, and I fear it is lost. It may have been sent to the British Museum, but I am not certain. I have not met with another instance. There was a small hole in the apex of the lcaf, and through it the ants came and went. The leaf looked as if all the mesophyllum had been cleared out and the epidermis blown out into a bladder. This observation may not be quite accurate as to the description of leaf, but I noted that the species of ant was the same.

"Here it is quite impossible to obtain a perfect rhinoceros skull, unless one has the good fortune to shoot it oneself, for the horn is so highly prized that it alone fetches from 200 to 300 rupees (Dutch guelders), being eagerly bought by the Chinese. It is believed in by all the natives as a sure and certain antidote for snake-bites and for purifying water. A respectable hadji affirmed to me with the persistency of belief that on his way to Mecca -he went in a native vessel-the stock of fresh water on board ran out, and that all on the vessel, by drinking sea-water out of a rhinoceros horn, found it to be--not salt water!"

\section{ON THE FERTILISATION OF COBAEA PENDULIFLORA (HOOK. FIL.)}

COBAEA PENDULIFLORA is a graceful climber, growing rather sparingly in our mountain-forests. It was described and figured by Karsten under the name of Rosenbergia penduliflora ("Flora.Columbix," I. 27, t. ix.), and afterwards in the Bot. Mag., i. 5757. Karsten's plate is very pretty, but in all the specimens $I$ have seen the linear lobes of the corolla were never so red as he paints them, nor do the stamens ever hang straight downwards parallel to the style, as his figure shows. The plate in the Botanical Magazine has only one defect, the artist having overlooked the hooklets and the ends of the tendrils.

The plant grows exceedingly quickly when kept in shade. A specimen now in my garden was raised from seed sown October 3, 1879, which sprang up a fortnight later, and covered, in less than three months, a wall twelve feet high and ten feet long. It climbs exactly in the same manner as Cobaea scandens, described by Darwin in his "Climbing Plants." The flowers have very little to attract attention, their colour being dull green, with very little red on the filaments, and there is no smell. Though not of great horticultural interest, the plant fully deserves the attention of the botanist on account of the peculiar circumstances under which the flowers are fertilised. Sir J. D. Hooker has made already some pertinent remarks on 